\title{
A Positron Emission Tomography Study of the Short-Term Maintenance of Verbal Information
}

\author{
Julie A. Fiez, ${ }^{1,3}$ Elizabeth A. Raife, ${ }^{1}$ David A. Balota, ${ }^{5}$ Jacob P. Schwarz, ${ }^{1}$ Marcus E. Raichle, ${ }^{1,2,3,4}$ \\ and Steven E. Petersen $1,2,3,4,5$ \\ ${ }^{1}$ Departments of Neurology and Neurological Surgery, ${ }^{2}$ Anatomy and Neurobiology, ${ }^{3}$ Radiology, and ${ }^{4} T h e$ McDonnell \\ Center for Higher Brain Function, Washington University School of Medicine, St. Louis, Missouri 63110, and ${ }^{5}$ Department \\ of Psychology, Washington University, St. Louis, Missouri 63110
}

Positron emission tomography (PET) was used to investigate the functional brain anatomy associated with the short-term maintenance of linguistic information. Subjects were asked to retain five related words, unrelated words, or pseudowords silently for the duration of a 40 sec PET scan. When brain activity during these short-term maintenance tasks was compared with a visual fixation control task, increases were found bilaterally in the dorsolateral prefrontal cortex and cerebellum, and medially in the supplementary motor area. Furthermore, effects of stimulus condition and recall performance were found in the left frontal operculum. To investigate the role of articulatory systems in the maintenance of verbal information, regional activation was compared across the maintenance tasks and a covert articulation task (silent counting). The cerebellum was active in both task conditions, whereas activation in prefrontal regions was specific to the maintenance condition. Conversely, greater activation was found in a left middle insular region in the silent counting than in the maintenance tasks. Based on converging results in this and previous studies, dorsolateral prefrontal cortical areas appear to contribute to the maintenance of both verbal and nonverbal information, whereas left frontal opercular regions appear to be involved specifically in the rehearsal of verbal material. Contrary to results found in other studies of working memory, activation was not found in the inferior parietal cortex, suggesting that this area is involved in aspects of stimulus encoding and retrieval, which were minimized in the present study.

Key words: positron emission tomography; short-term memory; prefrontal cortex; language; working memory; neuroimaging
The ability to maintain and manipulate information "on-line" is referred to typically as "working memory" (Baddeley, 1986; Goldman-Rakic, 1994). Working memory is necessary to perform many common tasks, such as rehearsing a telephone number (Miller, 1956), solving a mathematical equation (Geary et al., 1991; Logie et al., 1994), imagining the rotation of an object (Hertzog and Rypma, 1991; Corballis and Sidey, 1993), and integrating information across sentence clauses (Just and Carpenter, 1992; Casey, 1993). Clearly, the domain of working memory is large and involves an array of cognitive operations. For this reason, we focus in this study on one important aspect of working memory: the maintenance of verbal information in an active, readily available state.

The design of our paradigm was influenced by the successful use of delayed response tasks in monkeys to isolate neural activity associated with short-term information maintenance (Fuster, 1973; Funahashi et al., 1989; Fuster, 1989; Goldman-Rakic, 1994). As the primary task condition in the present study, subjects were scanned while they attempted to maintain five items. The items

Received May 8, 1995; revised Sept. 5, 1995; accepted Oct. 4, 1995.

This work was supported by National Institutes of Health Grants NS06833, EY08775, and HL13851, the Charles A. Dana Foundation, and the McDonnell Center for the Study of Higher Brain Function. I.A.F. received additional support from the National Science Foundation and the Mr, and Mrs. Spencer T. Olin Program for Women. We thank Len Lich, John Hood, the staff of the Cyclotron Unit for technical assistance, and an anonymous reviewer for suggesting an analysis based on previously published results.

Correspondence should be addressed to Dr. Julie A. Fiez, P.O. Box 8111, Department of Neurology and Neurological Surgery, Washington University School of Medicine, St. Louis, MO 63110

Copyright (C) 1996 Society for Neuroscience $\quad 0270-6474 / 96 / 160808-15 \$ 05.00 / 0$ were presented before beginning each $40 \mathrm{sec}$ scan and were recalled after each scan ended. Thus, during each scan, encoding, retrieval, and decision components were minimized, in contrast to previous studies of working memory (Grasby et al., 1993; Jonides et al., 1993; Paulesu et al., 1993; Petrides et al., 1993a,b; Cohen et al., 1994; McCarthy et al., 1994; Smith et al., 1995; Awh et al., in press; Courtney et al., in press; Haxby et al., in press; Owen et al., in press). We also examined a silent articulation task in which subjects covertly rehearsed the digits $1-5$ repeatedly. By comparing the activity found during the maintenance task to that found during the silent counting task, we intended to explore the relationship between regions involved in the short-term maintenance of verbal information and those involved in covert articulation.

In addition to focusing primarily on regions involved in the short-term maintenance of information, we also were interested in investigating the contributions of preexisting representations to the maintenance process. For this reason; subjects performed the maintenance task with three types of lists: a list of five words from the same semantic category, a list of five words from five semantic categories, and a list of five pseudowords (pronounceable letter strings). In our own pilot work with longer lists of the same type as those incorporated into the present study, list-dependent performance effects were found: serial recall performance was higher for categorically related word lists compared with unrelated word lists which, in turn, had a higher serial recall performance than pseudoword lists. These results replicate previous work demonstrating that memory span is higher for words than for pseudowords even when articulation rate is equated (Hulme et al., 1991; Multhaup et al., in press). These differences in list difficulty 
were fortuitous because they produced differences in recall performance across subjects, allowing the relationship between performance and functional activation to bc cxplored.

\section{MATERIALS AND METHODS}

\section{Subjects}

Subjects were healthy volunteers recruited from the undergraduate and medical campuses of Washinglon University. All were strongly righthanded as judged by the Edinburgh handedness inventory (Raczkowski et al., 1974). Subjects were paid $\$ 75.00$ for their participation and gave informed consent in accordance with guidelines set by the Human Studies and the Radioactive Drug Research committees of Washington University. Data from nine subjects were excluded for the following reasons: (1) excessive artifacts caused by movement between scans [as determined by a visually based (Fox et al., 1987a) rating system and a mathematical algorithm]; (2) failure to perform the tasks as instructed (e.g., subjects repeated the items aloud during the scan); or (3) equipment malfunctions. Data were analyzed from 12 subjects: 11 women and 1 man with a mean age of $24 \pm 5$ years (range 1937 ).

\section{Materials}

Five stimuli were presented during each of three scans in which subjects performed a short-term maintenance task, as described below. The items were drawn from a pool of 30 words and 30 matched pseudowords. The word stimuli were selected from six categories (furniture, instruments, fabric types, body parts, clothing, and vegetables) of the Battig and Montague (1969) norms. For each category, we selected five of the top eight responses to yield a pool of 30 words across six conceptual categories. A matched pseudoword was created for each word by substituting one or more phonemes in each word (e.g., tiano was created for piano). All stimuli were four to seven letters long.

For the categorically related stimulus condition, the five words within one of the six categories were presented, counterbalancing the selected category across subjects. For the unrelated stimulus condition, one word was selected from each of the five remaining categories, counterbalancing the selected word from each category across subjects. For the pseudoword stimulus condition, one pseudoword matched to a word from each of the five remaining categories was selected, with the additional restriction that the pseudoword not be derived from a word presented in either the related or the unrelated stimulus condition. Again, the selection of the pseudowords was balanced across subjects.

Thus, the five items presented for each stimulus condition were chosen with the following conditions: (1) use of the items and categories was counterbalanced across subjects; (2) no word or matched pseudoword was presented more than once during a scanning session; and (3) no word in the unrelated list condition was related to any of the five words presented in the related list condition.

\section{Experimental procedure}

Nine scans were completed for each subject. Each of three task conditions (a visual fixation control task, a silent counting task, and a shortterm maintenance task) was repeated three times per subject. Within the short-term maintenance task, each of the three classes of stimuli (related words, unrelated words, and pseudowords) was presented once per subject.

Visual fixation control task. Subjects were told to stare at a $3 \times 3 \mathrm{~mm}$ black cross hair on a black background centered on an Apple highresolution $\mathrm{RGB}$ monitor. The monitor was suspended $\sim 35$ cm above each subject and placed in the middle of his or her field of view. Subjects performed the visual fixation task during scans 3,6 , and 9 .

Silent counting task. Subjects were told to repeat silently to themselves the number sequence " $1,2,3,4,5$ " at a rate of approximately once every $2 \mathrm{sec}$. They were instructed to maintain visual fixation on the cross hair, and they were discouraged from speaking and making mouth movements during each scan. To determine compliance with this instruction, electromyogram (EMG) electrodes were placed heneath the lower lip to record jaw and lip movements, and a microphone placed on the subject's chest was used to detect any audible vocalizations. Subjects with detectable EMG activity or audible vocalizations were excluded from further analysis. The silent counting task was performed during scans 1,4 , and 7 .

Short-term maintenance task. Subjects were shown five items on the display monitor before the start of the positron emission lomography (PET) scan. Items were presented below the fixation cross hair for $3 \mathrm{sec}$ each at a rate of one every $3.5 \mathrm{sec}$. Subjects were instructed to remember the presented items silently for $55 \mathrm{sec}$ after the presentation of the final item while maintaining visual fixation. Subjects were discouraged from speaking and making mouth movements while they were attempting to remember the presented stimuli. EMG electrodes and a microphone were used to determine compliance with this instruction. Fifty-five seconds after presentation of the final stimulus item, a tone binaurally played through small earphone speakers (Knowles insert receiver, model 1912, Amherst, MA) signaled subjects to say out loud as many of the presented items as they remembered.

The stimulus items were presented such that the final item was presented $1-13 \mathrm{sec}$ before the beginning of each scan. Thus, PET data were acquired for a $40 \mathrm{sec}$ interval during the $55 \mathrm{scc}$ maintenance period after the presentation of the final stimulus item. Because this maintenance period followed presentation of the stimuli and preceded verbal recall of the presented items, the sensory input during each scan was matched to that in the visual fixation control task. There was no motor output during any of the scans.

Subjects maintained the five items during scans 2, 5, and 8. For each of the different maintenance scans, subjects were presented with one of three stimulus types (described in greater detail above): categorically related nouns, unrelated nouns, and pseudowords. The order of the stimulus conditions was counterbalanced across the subjects.

\section{Apparatus and data acquisition}

The PETT VI tomograph was used in the low-resolution mode and acquired seven parallel slices simultaneously with a center-to-center distance of $14.4 \mathrm{~mm}$ (Ter-Pogossian et al., 1982; Yamamoto et al., 1982). For each scan, water labeled with the positron-emitting oxygen isotope ${ }^{15} \mathrm{O}$ was used as a blood-flow tracer. The ${ }^{15} \mathrm{O}$-labeled water was incorporated into a saline solution and administered as an intravenous bolus of $8-10 \mathrm{ml}$ of saline containing $48-74 \mathrm{mCi}$ (Welch and Kilbourn, 1985). Data were acquired over a $40 \mathrm{sec}$ interval and reconstructed using filtered back-projection to create images of the tracer distribution with an inplane resolution of $17 \mathrm{~mm}$. Because of the linear relationship between tissue radioactivity and blood flow (Herscovitch et al., 1983; Fox and Mintun, 1989), images of radioactive counts, not blood flow, were used. This eliminated the risk and discomfort of arterial catheterization. A relatively brief interval $(\sim 10 \mathrm{~min})$ between scans allowed radioactivity levels to return to baseline levels.

\section{RESULTS \\ Conventions for reporting response locations and magnitudes}

To isolate activity changes between task conditions, several steps were taken. First, to control for the effects of global fluctuations in activity and variations in the amount of isotope injected (Fox et al., 1987a), the number of counts measured in each image was normalized to 1000 . Ncxt, a 49 -slicc, lincarly interpolated image was created from the seven slices of a reconstructed image from a single scan (Fox et al., 1988). Finally, the interpolated image generated during performance of one task by a given subject was subtracted on a pixel-by-pixel basis from the interpolated image generated during performance of another task by the same subject. The resultant images will be referred to as individual difference images. Magnitude changes observed in difference images will be given in terms of normalized counts (e.g., a peak in a difference image with a magnitude of +100 counts represents an $\sim 10 \%$ increase in activity or blood flow).

To allow comparisons to be made across subjects, each image was cast into the space of the Talairach stereotactic atlas (Fox et al., 1985; Talairach and Tournoux, 1988). The transformations were based on skull dimensions obtained from a lateral skull $x$ ray (Fox et al,, 1985). A focus will be reported by listing three coordinates $(x, y, z)$ : the $x$-coordinate is the distance in millimeters to the right $(+)$ or left $(-)$ of midline, the $y$-coordinate is the distance in millimeters anterior $(+)$ or posterior $(-)$ to the anterior commissure, and the $z$-coordinate is the distance in millimeters above $(+)$ or below $(-)$ a horizontal plane that cuts 
through the anterior-posterior commissures. In addition to presenting coordinates to describe the locations of identified regions, we also will refer to response locations in terms of the 52 cortical areas described by Brodmann (1909). Our localization of these areas is based only on the gross neuroanatomical boundaries defined by Talairach and Tournoux (1988) and, therefore, should be regarded merely as descriptive labels rather than histologically accurate terms (Rajkowska and Goldman-Rakic, 1995a,b).

\section{Identification of significant regions of change within each task condition}

Several issues complicate the selection of an appropriate statistical measure for analyzing PET difference images. First, PET is a noisy technique, and data must be combined in some manner across individual difference images. Second, the locations of significant change often may not be known or hypothesized a priori; this presents a difficult statistical problem because each image is composed of a potentially large number of spatial locations (>300,000 voxels) with a small number of observations (usually 8-12 subjects perform each active and control task). The issue of statistical analysis of PET activation studies is an active area of investigation in many laboratories.

Although several thresholding techniques have been proposed to define statistically significant responses without a priori regions of interest (Fox et al., 1988; Ford et al., 1991; Friston et al., 1991; Worsley et al., 1992), these methods are limited by the difficulty of selecting a threshold that minimizes false positives while including the most reliable regions of change (Hunton et al., 1994). Thus, although the identified responses are likely to reflect real biological changes, many other real regions of change may be overlooked. To address this problem while minimizing the subjects' exposure to radiation, we used a two-stage, regions-of-interest approach. In the first stage (the hypothesis-gencration stage), a portion of the entire data set was used to generate regions without a priori assumptions about their locations. In the second stage (the hypothesis-testing stage), standard statistical tests were used to determine whether significant activation could be found in the identified regions in a second, and independent, data set. For this first analysis, the data from the different task conditions were collapsed together to focus on regions of common activation in each task condition.

The 36 individual difference images from each task condition ( 3 maintenance minus fixation task scans from each of 12 subjects, and 3 silent counting minus fixation task scans from each of 12 subjects) were divided into two groups. A hypothesis-generating group was created for each task condition by taking 1 image from each subject to give $n=12$ images per task condition. The remaining images from each task condition formed a hypothesistesting group of images consisting of 24 images per task condition ( 2 images from each subject). The images in each group were selected such that list condition, scan order, and overall subject performance were balanced (e.g., within both the hypothesisgenerating and hypothesis-testing group of images, one-third of the images was from the related word list condition, one-third was from the unrelated word list condition, and one-third was from the pseudoword list condition). In addition, none of the difference images in the hypothesis-generating group was created using fixation control images that also were used in the hypothesistesting group of images. Thus, the two groups of individual difference images were independent of each other.

For each condition, data from the hypothesis-generating group of images were used to identify candidate regions of interest. This was done by averaging together the 12 images from each task condition on a pixel-by-pixel basis to create a hypothesis-generation mean difference image for each task condition. Foci of change in each mean difference image were identified using an automated peak detection algorithm (Mintun et al., 1989). For each focus, the location (in $x, y$, and $z$ stereotactic coordinates), magnitude, and $t$ value of the maximal change were computed (Mintun et al., 1989). Each positive and negative focus with a change of 25 counts or greater and with a descriptive $t$ value $>2.2$ (under appropriate conditions, $t_{(11)}-2.2$ would be equivalent to $p-0.05$ ) was used to define the center of a spherical region-of-interest with a radius of $7 \mathrm{~mm}$. The $7 \mathrm{~mm}$ radius was chosen because this value corresponds to the resolution of the algorithm used to identify automatically all regions of change in individual and average difference images (Mintun et al., 1989). The 25 count magnitude cutoff was chosen because above this level the percentage of regions found to be significantly active in an independent data set diverges from the percentage expected by chance (Hunton et al., 1994); the $t$-value cutoff was used to select regions with the least variability and, thus, with the greatest likelihood of reaching significance in the hypothesis-testing data set.

After the regions of interest for each task condition were defined, they were applied to data from the hypothesis-testing group of individual difference images for each task condition. Individual regional magnitude values were computed by calculating the average magnitude of all pixels located inside the region. Differences in brain size and subject placement in the scanner caused some regions to be sampled incompletely in all subjects. If $>10 \%$ of a region was not sampled in a subject, the magnitude values from that subject were excluded from subsequent analyses. For each region, the regional magnitude was calculated for each of the 24 individual difference images in the hypothesis-testing group, and the two valucs from cach subject wcre averaged to yield a mean regional activation for each of the 12 subjects. The 12 values for each region were then submitted to a one-sample one-tailed $t$ test. The results were Bonferroni-corrected for the number of positive or negative comparisons.

Finally, a descriptive analysis of the entire data set was performed to help compare the two-stage, regions-of-interest analysis with the more typical analyses based on an evaluation of pixel $t$ values across an entire image. For each task condition, the three individual difference images from each subject first were averaged together. Then, the 12 difference images ( 1 per subject) were used to create a t-image for each task condition and, for each identified region, the location of the nearest peak and the $t$ value at this location were identified.

\section{Regions of significant change in the maintenance condition}

Four of 16 candidate regions of positive change identified in the maintenance minus fixation mean difference image were found to be significant in the hypothesis-testing group of maintenance minus fixation images ( $p<0.05$, one-tailed $t$ test, Bonferroni-corrected for 16 comparisons), as summarized in Table 1 and Figure 1. One region of positive change was located in the medial frontal gyrus (at or near Brodmann area 6 ), two were located in the middle frontal gyrus bilaterally (at or near Brodmann areas 9 and 46), and the fourth region was located near the midline of the cerebellum. Two additional cerebellar regions and a region located in the left inferior frontal gyrus (at or near Brodmann area 45), showed a strong trend toward positive activation $(p<0.05$, one-tailed onesample $t$ test, before Bonferroni correction). 
Table 1. Identification of positive changes in the maintenance minus fixation condition

Regions from hypothesis group

\begin{tabular}{|c|c|c|c|c|c|c|c|c|c|c|c|}
\hline \multicolumn{4}{|c|}{ 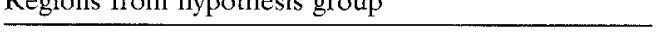 } & \multirow{2}{*}{\multicolumn{4}{|c|}{ Regional statistics (in test group) }} & \multicolumn{4}{|c|}{ l-millage statisties } \\
\hline \multirow[b]{2}{*}{ Brodmann area } & \multicolumn{3}{|c|}{ Location } & & & & & \multicolumn{3}{|c|}{ Nearest peak } & \multirow{2}{*}{$\begin{array}{l}\text { peak } \\
t \text { val }\end{array}$} \\
\hline & $x$ & $y$ & $z$ & mag & df & $t \mathrm{val}$ & $p$ val & $x$ & $y$ & $z$ & \\
\hline \multicolumn{12}{|l|}{ Cerebellum } \\
\hline Cerebellum (L) & -17 & -77 & -24 & 28 & 7 & 3.26 & $0.0069^{a}$ & -25 & -73 & -27 & 9.55 \\
\hline Cerebellum (L) & -9 & -47 & -22 & 20 & 7 & 3.88 & $0.0030^{b}$ & -11 & -49 & -16 & 4.01 \\
\hline Cerebellum (R) & 27 & -63 & -14 & 20 & 11 & 2.15 & $0.0275^{a}$ & 25 & -59 & -25 & 6.41 \\
\hline \multicolumn{12}{|l|}{ Frontal } \\
\hline BA 6 (med) & 1 & 9 & 50 & 45 & 11 & 6.43 & $0.0001^{b}$ & -1 & 9 & 52 & 14.83 \\
\hline $\mathrm{BA} 9(\mathrm{R})$ & 33 & 33 & 34 & 30 & 11 & 3.77 & $0.0016^{b}$ & 27 & 25 & 32 & 6.12 \\
\hline $\mathrm{BA} 9(\mathrm{~L})$ & -37 & 45 & 30 & 16 & 11 & 3.40 & $0.0030^{b}$ & -39 & 49 & 18 & 8.94 \\
\hline BA $44 / 45(\mathrm{~L})$ & -59 & 13 & 14 & 13 & 11 & 1.91 & $0.0410^{a}$ & -59 & 17 & 12 & 5.08 \\
\hline \multicolumn{12}{|l|}{ Nonreplicating } \\
\hline Cerebellum (L) & -55 & -27 & -10 & 13 & 11 & 1.52 & 0.0785 & -57 & -25 & -19 & 4.12 \\
\hline Cerebellum (L) & -53 & -51 & -18 & 18 & 9 & 1.80 & 0.0524 & -55 & -53 & -23 & 4.07 \\
\hline BA $19(\mathrm{~L})$ & 11 & 55 & 2 & 0 & 11 & -0.04 & 0.5135 & -19 & -67 & 6 & 1.22 \\
\hline BA $9(\mathrm{~L})$ & -35 & 31 & 32 & 19 & 11 & 1.74 & 0.0547 & -33 & 31 & 32 & 3.42 \\
\hline BA $45(\mathrm{~L})$ & -29 & 25 & 4 & 13 & 11 & 1.47 & 0.0849 & -25 & 17 & 4 & 4.72 \\
\hline BA 47 (R) & 51 & 27 & -6 & 10 & 10 & 0.92 & 0.1886 & 53 & 25 & -4 & 3.57 \\
\hline BA $10(\mathrm{~L})$ & -35 & 57 & -6 & 11 & 9 & 1.44 & 0.0915 & -31 & 53 & 0 & 4.04 \\
\hline BA 32 (med) & 3 & 29 & 14 & -1 & 11 & -0.08 & 0.5306 & 7 & 30 & 32 & 8.60 \\
\hline BA 7 (L) & -13 & -69 & 44 & 17 & 8 & 1.58 & 0.0759 & -19 & -72 & 38 & 4.82 \\
\hline
\end{tabular}

${ }^{a}$ Uncorrected $p<0.05$.

${ }^{b} p<0.05$ with Bonferroni correction for 16 comparisons.

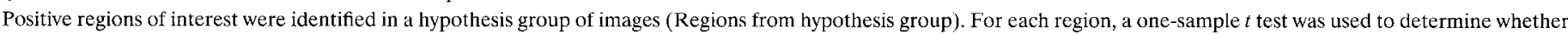

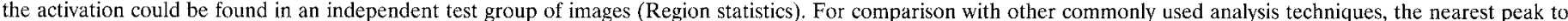

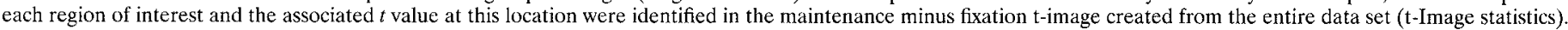

Three of 25, candidate regions of negative change were found to be significant in the hypothesis-testing group of images $(p<0.05$, one-tailed one-sample $t$ test, Bonferroni-corrected for 25 comparisons), as summarized in Table 2 and Figure 2. These changes were located in the medial occipital gyrus (at or near Brodmann area 18), middle temporal gyrus (at or near Brodmann areas 39 and 22), and the insula. Several other regions showed a strong trend toward a negative change $(p<0.05$, one-tailed $t$ test, before Bonferroni correction). In general, these negative changes were located posteriorly and included changes that localized at or near portions of the cingulate (Brodmann areas 23 and 30), postcentral and precentral (Brodmann areas 3 and 4), and parietal and temporal (Brodmann areas 39, 40, and 41) gyri.

In general, the results from the regions-of-interest analysis were in good agreement with the descriptive $t$ values computed from the entire data set. For nearly all regions that showed either a significant or near-significant $(p<0.05$ before Bonferroni correction) activation change, the nearest peak in the t-image created from the entire data set had a $t$ value within the range generally considered to be significant when statistical thresholding techniques are applied (i.e., uncorrected $p<0.001$ ). Overall, the regions-of-interest approach appears to be a slightly more conservative approach to the data analysis. This probably reflects the fact that, for the regions-of-interest analysis, the magnitudes were averaged across a $7 \mathrm{~mm}$ radius sphere, whereas the values from the t-image reflect peak values at a single voxel. Additionally, the locations of the regions were defined based on a different data set from which they were tested and, therefore, were not centered on the locations of the maximum change in the entire data set.

\section{Regions of significant change in the silent counting condition}

One of the 16 candidate regions of positive change identified in the silent counting minus fixation mean difference image was found to be significant in the hypothesis-testing group of silent counting minus fixation images $(p<0.05$, one-tailed $t$ test, after Bonferroni correction for 16 comparisons). The region was located at or near the left insula (Table 3 ). None of the 13 candidate regions of negative change was changed significantly in the hypothesis-testing group of images ( $p<0.05$, one-tailed $t$ test, after Bonferroni correction for 13 comparisons; see Table 3). Two regions showed a strong tendency to be changed negatively in the silent counting minus fixation condition $(p<0.05$, one-tailed $t$ test, before Bonferroni correction). The regions were located on the left, in the anterior cingulate gyrus (at or near Brodmann area 32 ), and the left inferior frontal gyrus (at or near Brodmann area 45; see Table 3).

\section{Activation of regions across task conditions}

To our surprise, there was no overlap between the regions identified in the maintenance minus fixation and the silent counting minus fixation conditions. To explore this issue further, the similarities in regional activation were examined directly across the two task conditions. The regions of interest were those areas of change that were significant in either the memory minus fixation condition or the silent counting minus fixation condition. Thus, there were four positive and three negative regions of change identified in the memory minus fixation condition, and one positive region of change identified in the silent counting minus fixation condition. For each region of interest identified in one condition, regional magnitudes 


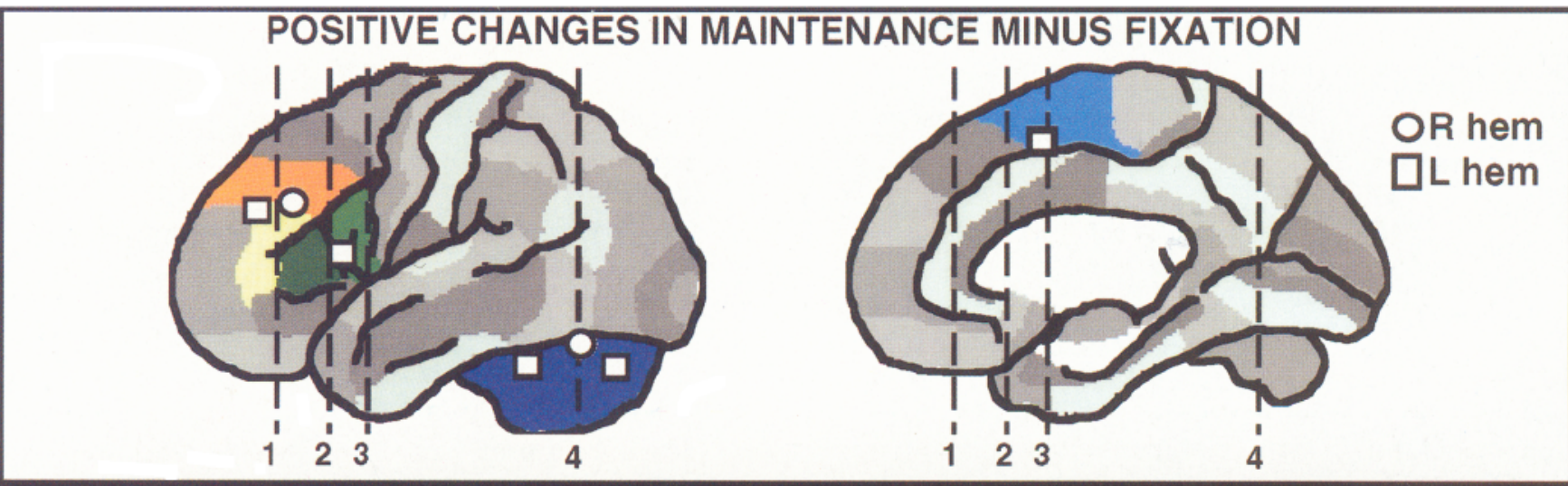

A) MAINTENANCE
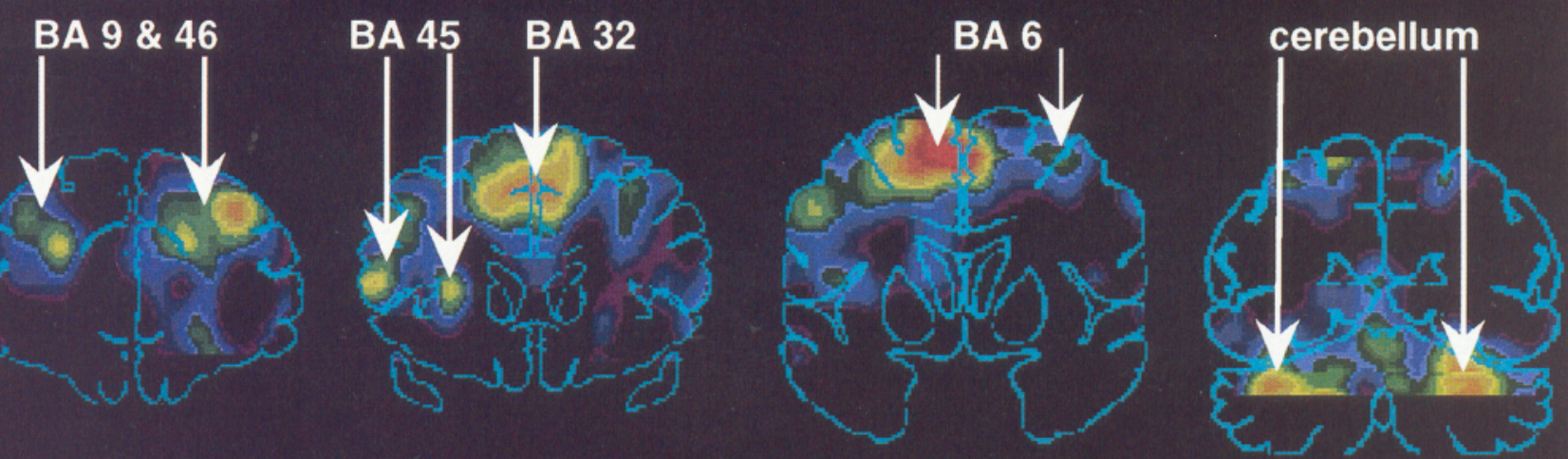

(1) $Y=37$

(2) $Y=19$

(3) $Y=5$

(4) $Y=-65$

B) SILENT COUNTING

$\mathbf{L}$

$\mathbf{R}$
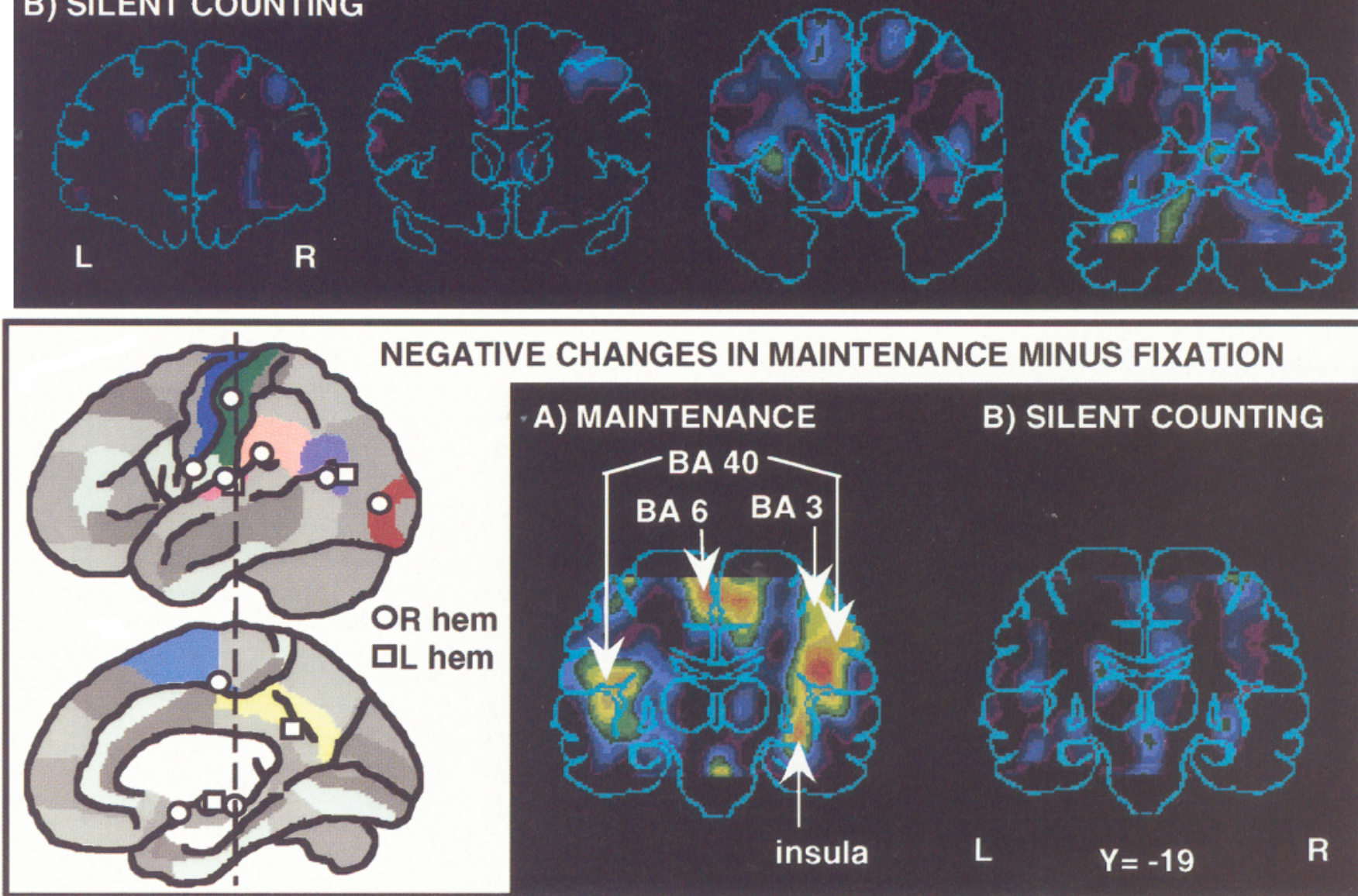

-A) MAINTENANCE

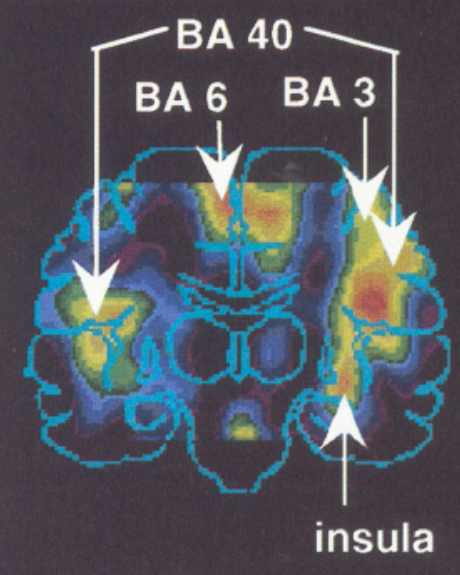

B) SILENT COUNTING

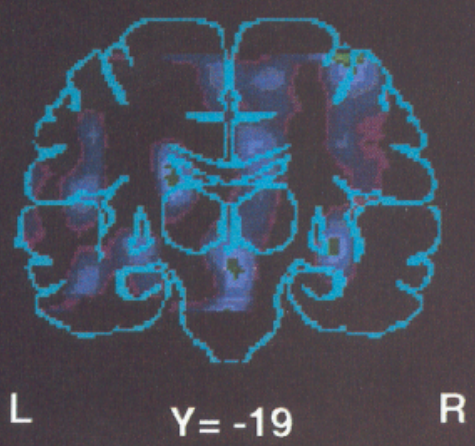


Table 2. Identification of negative changes in the maintenance minus fixation condition

Regions from hypothesis group

\begin{tabular}{|c|c|c|c|c|c|c|c|c|c|c|c|}
\hline \multicolumn{4}{|c|}{ 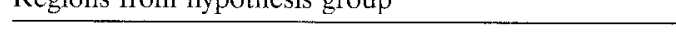 } & \multirow{2}{*}{\multicolumn{4}{|c|}{ Region statistics (in test group) }} & \multicolumn{4}{|c|}{ te-111age statistics } \\
\hline \multirow[b]{2}{*}{ Brodmann area } & \multicolumn{3}{|c|}{ Location } & & & & & \multicolumn{3}{|c|}{ Nearest peak } & \multirow{2}{*}{$\begin{array}{l}\text { peak } \\
t \text { val }\end{array}$} \\
\hline & $x$ & $y$ & $z$ & mag & df & $t$ val & $p$ val & $x$ & $y$ & $z$ & \\
\hline \multicolumn{12}{|l|}{ Medial } \\
\hline BA $6 / 24(\mathrm{R})$ & 13 & -17 & 44 & -29 & 11 & -3.58 & $0.0022^{a}$ & 7 & -23 & 48 & 8.51 \\
\hline Basal ganglia (R) & 17 & 5 & -8 & -20 & 11 & -2.42 & $0.0169^{a}$ & 17 & -4 & -4 & 7.68 \\
\hline BA $23(\mathrm{~L})$ & -17 & -49 & 28 & -10 & 11 & 2.55 & $0.0135^{a}$ & -14 & -48 & 28 & 8.39 \\
\hline Insula (R) & 35 & -23 & -2 & -28 & 11 & -4.57 & $0.0004^{b}$ & 35 & -21 & 0 & 7.77 \\
\hline Insula (L) & -27 & -13 & -4 & -18 & 11 & -2.83 & $0.0082^{a}$ & -25 & -14 & -8 & 10.00 \\
\hline \multicolumn{12}{|l|}{ Lateral } \\
\hline Insula/BA 41 (R) & 39 & -11 & -4 & -21 & 11 & -3.14 & $0.0047^{a}$ & 43 & -7 & 4 & 7.04 \\
\hline BA 4/insula (R) & 29 & 1 & 20 & -19 & 11 & -1.84 & $0.0462^{a}$ & 23 & 3 & 12 & 3.96 \\
\hline BA $3 / 4(\mathrm{R})$ & 41 & -21 & 54 & -23 & 7 & -2.91 & $0.0114^{a}$ & 45 & -19 & 55 & 6.45 \\
\hline BA $40 / 41(\mathrm{~L})$ & -43 & -23 & 10 & -24 & 11 & -2.55 & $0.0134^{a}$ & -45 & -19 & 4 & 3.95 \\
\hline BA 40/41 (R) & 41 & -21 & 16 & -28 & 11 & -2.97 & $0.0063^{a}$ & 38 & -17 & 28 & 10.53 \\
\hline BA 40/insula (R) & $\therefore \quad 25$ & -35 & 28 & -12 & 11 & -2.06 & $0.0319^{a}$ & 25 & -33 & 24 & 5.87 \\
\hline BA $39 / 19(\mathrm{~L})$ & -45 & -77 & 14 & -22 & 11 & -2.26 & $0.0226^{a}$ & -51 & -83 & 10 & 5.84 \\
\hline BA $39 / 22$ (R) & 35 & -61 & 14 & -25 & 11 & -4.35 & $0.0006^{b}$ & 39 & -53 & 18 & 6.36 \\
\hline BA $18(\mathrm{R})$ & 35 & -85 & 6 & -28 & 11 & -4.22 & $0.0007^{b}$ & 35 & -81 & 10 & 9.61 \\
\hline \multicolumn{12}{|l|}{ Nonreplicating } \\
\hline BA 4 (med) & -7 & -33 & 50 & -15 & 9 & -1.70 & 0.0613 & -8 & -25 & 54 & 18.39 \\
\hline BA $31 / 30$ (med) & 9 & -51 & 22 & -9 & 11 & -1.07 & 0.1530 & 3 & -55 & 26 & 4.57 \\
\hline $\mathrm{BA} 40(\mathrm{R})$ & 49 & -35 & 26 & -11 & 11 & -1.30 & 0.1101 & 59 & -43 & 24 & 1.89 \\
\hline BA $2(\mathrm{~L})$ & -45 & -25 & 48 & -9 & 10 & -1.11 & 0.1466 & -48 & -26 & 56 & 1.81 \\
\hline BA 40/insula (L) & -31 & -41 & 10 & -6 & 11 & -1.26 & 0.1166 & -33 & -33 & 18 & 4.98 \\
\hline BA $18(\mathrm{R})$ & 19 & -93 & 4 & -14 & 11 & -1.58 & 0.0714 & 35 & -97 & 4 & 5.51 \\
\hline BA $18(\mathrm{~L})$ & -21 & -93 & 8 & -9 & 11 & -0.87 & 0.2018 & -29 & -91 & 0 & 4.19 \\
\hline BA $19(\mathrm{~L})$ & -31 & -71 & 22 & -5 & 11 & -0.79 & 0.2236 & -31 & -81 & 24 & 8.36 \\
\hline BA $17(\mathrm{R})$ & 27 & -65 & 12 & -5 & 11 & -0.50 & 0.3133 & 15 & -59 & 2 & 2.41 \\
\hline $\mathrm{BA} 17(\mathrm{R})$ & 13 & -83 & 6 & 2 & 11 & 0.21 & 0.5795 & $c$ & & & \\
\hline BA $7 / 40(L)$ & -27 & -29 & 32 & -7 & 11 & -0.89 & 0.1953 & -23 & -37 & 44 & 2.20 \\
\hline
\end{tabular}

Uncorrected $p<0.05$

${ }^{b} p<0.05$ with Bonferroni correction for 25 comparisons.

${ }^{c}$ No peak found within $20 \mathrm{~mm}$ of region.

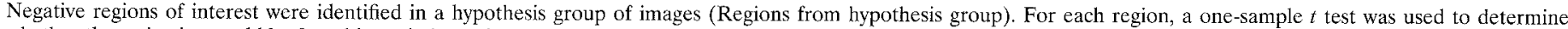

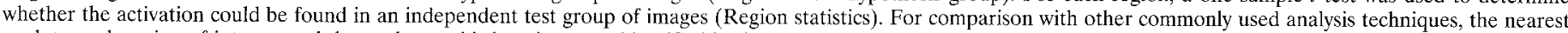

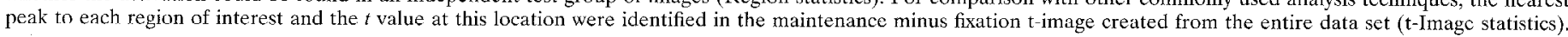

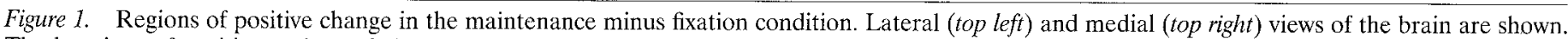

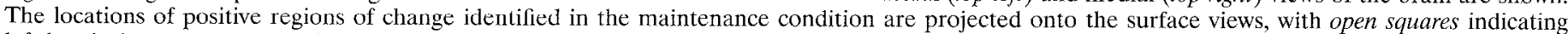

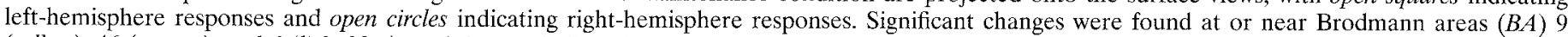

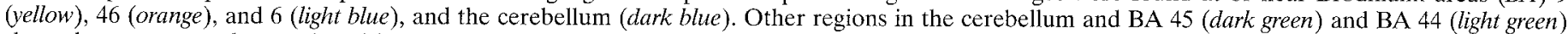

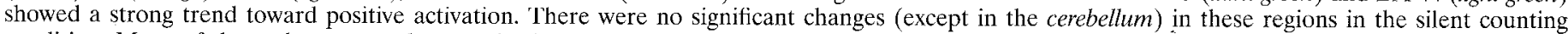

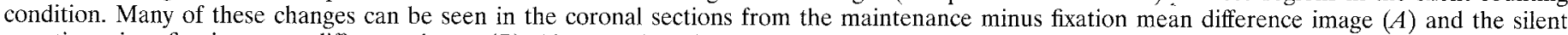

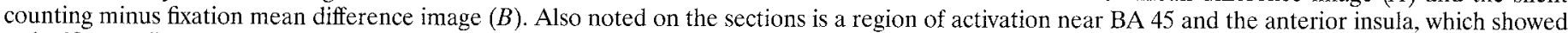

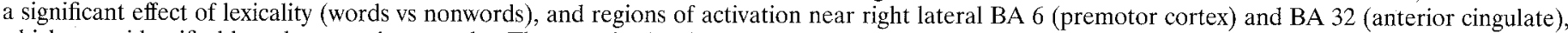

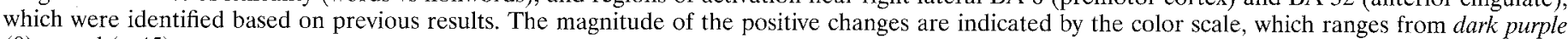
(0) to red $(+45)$.

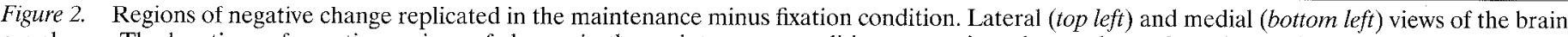

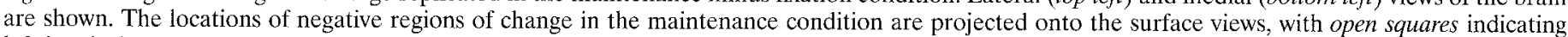

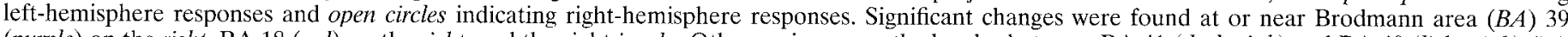

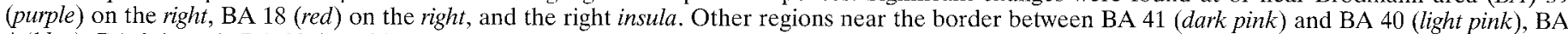

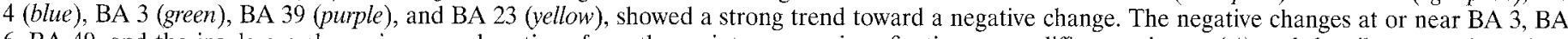

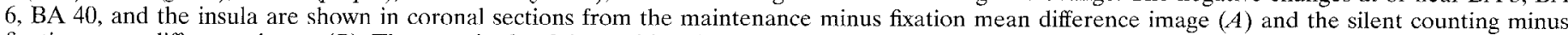

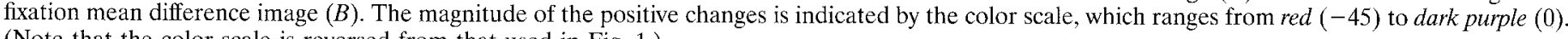
(Note that the color scale is reversed from that used in Fig. 1.) 

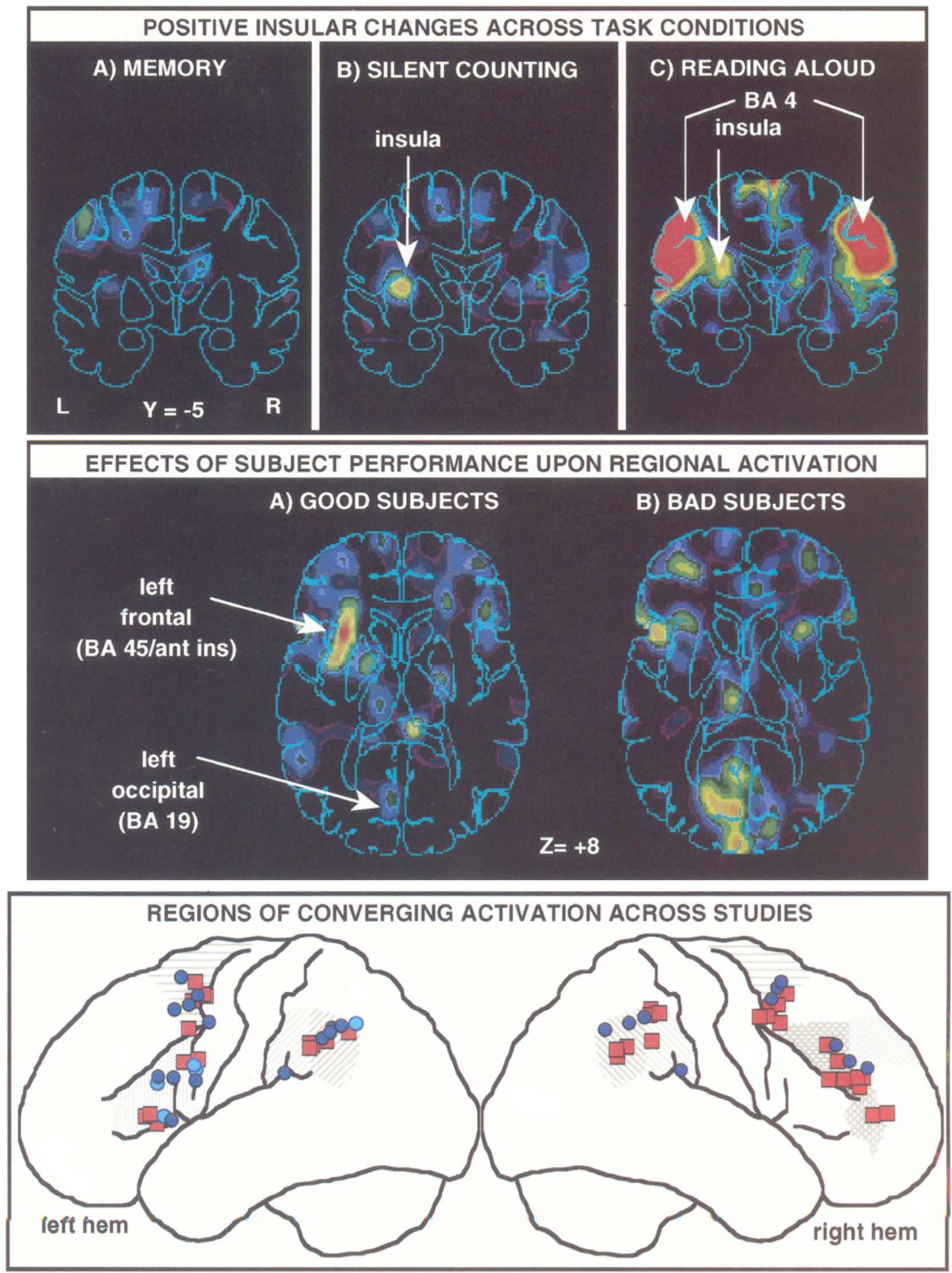
Table 3. Identification of positive and negative changes in the silent counting minus fixation condition

Regions from hypothesis group

\begin{tabular}{|c|c|c|c|c|c|c|c|}
\hline \multirow[b]{2}{*}{ Brodmann area } & \multicolumn{3}{|c|}{ Location } & \multicolumn{4}{|c|}{ Region statistics (in test group) } \\
\hline & $x$ & $y$ & $z$ & mag & df & $t$ val & $p$ val \\
\hline \multicolumn{8}{|l|}{ Positive changes } \\
\hline Insula (L) & -37 & -3 & 8 & 31 & 11 & 3.66 & $0.0019^{b}$ \\
\hline \multicolumn{8}{|l|}{ Negative changes } \\
\hline BA $32(\mathrm{~L})$ & -19 & 41 & 0 & -15 & 11 & -2.06 & $0.0317^{a}$ \\
\hline BA 45/insula (L) & -35 & 25 & 6 & -17 & 11 & -1.82 & $0.0479^{a}$ \\
\hline
\end{tabular}

t-Image statistics

$\begin{array}{lll}\text { Nearest peak } & & \\ x & z & t \text { peak }\end{array}$

$-33--3$

8

7.66

\section{$-17$}

39

2

4.19

$\begin{array}{lll}-32 & 21 & 4\end{array}$

5.03

${ }^{b} p<0.05$ with Bonferroni correction for 16 positive/13 negative comparisons.

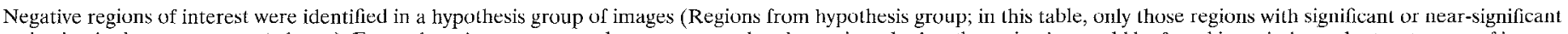

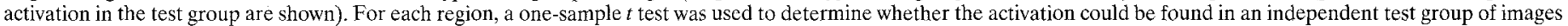

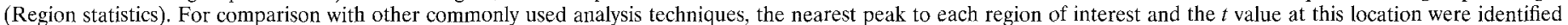
in the silent counting minus fixation t-image creatcd from the entire data set (t-Image statistics)

were determined for the 36 individual difference images comprising the other task condition. The three regional magnitude values from each subject were averaged together and submitted to a one-sample two-tailed $t$ test. The results were Bonferronicorrected for the number of positive or negative comparisons across each task condition.

In only two regions was significant activation found in both the maintenance and the silent counting conditions $(p<0.05$ after Bonferroni correction). A midline cerebellar region $(x=-9, y=$ $-47, z=-22$ ) had a mean magnitude of 20 counts in the maintenancc condition $\left(t_{(7)}=3.88\right)$ and a mean magnitude of 20 counts in the silent counting condition $\left(t_{(7)}=5.45\right)$. Additionally, a left insular region $(x=-27, y=-3, z=8)$ had a mean magnitude of 31 counts in the silent counting condition $\left(t_{(11)}=\right.$ 3.66) and a mean magnitude of 11 counts in the maintenance condition $\left(t_{(11)}=2.62\right)$; in the insular region, the activation in the silent counting condition was found to be significantly greater than that found in the maintenance condition $\left(t_{(1,11)}=2.29, p=\right.$ 0.043). For visual comparison of the two task conditions, see Figures 1, 2, and 3 .

\section{Effects of stimulus manipulations in memory maintenance condition}

The regions of change identified in maintenance minus fixation condition were characterized more fully by determining the effects of list type (related words, unrelated words, or pseudowords) on the magnitude of regional changes. Two stimulus comparisons were performed: related versus unrelated word lists and lexical (related and unrelated word lists) versus pseudoword lists.

As regions of interest, we used all of the maintenance minus fixation regions of interest identified in the hypothesis-generating stage of the analysis. Regions that failed to reach significance in the hypothesis-testing stage still were evaluated for the effects of stimulus type and performance; variability introduced by these differences may explain why the regions were not found to be significantly changed in the hypothesis-testing group (because data were collapsed across performance and stimulus conditions for the analysis). For each region, individual regional magnitudes were determined for each of the 36 maintenance minus fixation individual difference images to obtain 3 values (magnitude in related, unrelated, and pseudoword conditions) for each of the 12 subjects, which were analyzed as described below.

\section{Comparison between related and unrelated word stimuli}

To assess differences between the two word conditions, for each region a paired two-tailed $t$ test was used to compare the magnitudes in the related word versus unrelated word conditions across subjects. The results were Bonferroni-corrected for the number of positive or negative comparisons.

$\leftarrow$

Figure 3. Left insular changes across three task conditions. Coronal sections taken $5 \mathrm{~mm}$ posterior to the anterior commissure are shown for the memory maintenance minus fixation $(A)$ and silent counting minus fixation $(B)$ conditions of the present study. For comparison, also shown is a section from an overt reading (read aloud, visually presented words) minus fixation condition examined in a separate group of subjects (Fiez et al., 1993) (C). Significant positive left insular activation was found in the silent counting and the overt reading conditions, but not in the maintenance condition. Bilateral activation at or near primary motor cortex also can be seen in the overt reading condition. The magnitude of the positive changes is indicated by the color scale, which ranges from dark purple $(0)$ to red $(+50)$.

$\leftarrow$

Figure 4. Differences in regional activation in subjects with good versus bad performance. Horizontal sections taken $8 \mathrm{~mm}$ above the anterior-posterior plane are shown for the pseudoword maintenance minus fixation list condition for two subject groups: those with perfect pseudoword recall ( $G O O D$ $S U B J E C T S$ ) and those who missed one or more items (BAD SUBJECTS). Whereas the left frontal region (BA 45/ant ins) was larger in the good versus the bad subjects, the opposite pattern was found in the occipital region $(B A 19)$.

$\leftarrow$

Figure 5. Convergence of results across PET studies. Left and right lateral views of the brain are shown. The approximate extent of Brodmann areas (BA) 9 and 46 (dorsolateral prefrontal cortex) on the right are indicatcd by dark stippling, BA 44/45 (frontal opercular cortex) on the left by light stippling, BA 40 (inferior parietal cortex) by slanted lines, and lateral BA 6 (premotor cortex) by horizontal lines. Activation in the frontal operculum is found in a variety of verbal tasks in which the working memory demands are minimal or relatively balanced between active and control states (light blue circles), but generally not in dorsolateral prefrontal and premotor cortex. For verbal working memory tasks (dark blue circles), activation can be found in frontal opercular cortex as well as in dorsolateral prefrontal, inferior parietal, and premotor cortex. For nonverbal working memory tasks (red squares), activation at or near dorsolateral prefrontal, premotor, and inferior parietal cortex is found. 
Of the 16 positive and 25 negative regions, no significant differences between the related and unrelated word conditions were found ( $p>0.05$, after Bonferroni corrcction for 16 positive and 25 negative comparisons).

\section{Effects of stimulus lexicality}

To assess lexicality effects, for each region the magnitude values in the unrelated and related word stimulus conditions within each subject were averaged together to yield a mean regional activation for lexical (word-level) lists of stimuli. A two-tailed paired $t$ test then was used to compare the averaged word versus pseudoword list condition regional magnitudes. The results were Bonferronicorrected for the number of positive or negative comparisons.

In general, a trend was found for a greater magnitude of change in the pseudoword than in the word list conditions for both positive and negative regions of change. In 8 of 16 regions of positive change, the mean pseudoword magnitude was $>10$ counts greater (more positive) than the mean magnitude in the word conditions, versus only 2 regions showing the opposite pattern; in 9 of 25 regions of negative change, the mean pseudoword magnitude was $>10$ counts greater (more negative) than the mean magnitude in the word conditions, versus 5 regions showing the opposite pattern.

These differences between the activation found in the word versus the nonword list conditions reached significance in only one region. For this frontal opercular region located near the border between Brodmann area 45 and the insula $(x=-29, y=$ $25, z-4$ ), significantly greater activation was found in the pseudoword list condition than in the related and unrelated word list conditions (mean pseudoword magnitude $=42$ counts, mean word magnitude $=6$ counts; $t_{(1,10)}=4.46, p<0.05$ after Bonferroni correction for 16 comparisons). This region appears to be distinct from a more lateral and posterior region near the border between Brodmann areas 44 and 45; activation within this more lateral region approached significance in the hypothesis test group, but no significant effect of lexicality was found (see Table 1; Fig. 1).

\section{Effects of performance}

Whereas the differences between list conditions were planned, the differences in subject performance were noted post hoc. Although all subjects were at ceiling on "recalling the lists of words, a performance difference was noted between subjects in the pseudoword condition: 6 of the 12 subjects recalled all five of the pseudoword stimuli, whereas the remaining 6 subjects correctly recalled only three or four pseudoword stimuli. Thus, subjects were divided into two groups: the "good" subjects were defined as those with perfect recall of all items, and the "bad" subjects were defined as those who failed to recall all items successfully.

To explore this behavioral difference, mean difference images were created for each of the two subject groups: an $n=6$ "good performance" pseudoword maintenance minus fixation image, and an $n=6$ "bad performance" pseudoword maintenance minus fixation image. Visual inspection of these images (Fig. 4) revealed striking differences between the images in two regions: a left frontal opercular region $(x=-29, y=15, z=6)$, which appeared to be more active in the "good performance" than in the "bad performance" image, and a left occipital region $(x=7, y=79$, $z=6$ ), which appeared to be more active in the "bad performance" than in the "good performance" image. Regional magnitudes within each of these two regions were computed in the 12 pseudoword minus fixation individual difference images. A per- formance (good vs bad) by region (left frontal opercular vs left occipital) ANOVA revealed that there was a significant interaction between the two factors $\left(F_{(1,10)}=5.74, p=0.038\right)$, suggesting that the visually observed difference was reliable. However, this result should be treated cautiously, because in the present study the sample sizes did not permit an independent replication of the results.

Both the frontal opercular region found in the "good performers" and the region that showed an effect of stimulus lexicality (discussed above) are located near the border between the anterior insula and the inferior frontal gyrus (at or near Brodmann area 45), suggesting that the two regions are related functionally and anatomically. Because the data sets used to identify these two regions differed, some variability in their location was expected; further experiments within the same group of subjects will be necessary to resolve the relationships between the various frontal opercular regions identified in the present study. Activation within the occipital cortex was not identified in the hypothesis-generation data set, most likely because of the performance-related variability found across subjects.

\section{Comparison with other studies of working memory and phonological processing}

As discussed in the introductory remarks, a number of studies published previously have focused on different aspects of working memory and phonological processing. To explore similarities and differences between these previous studies and the present results, an additional analysis was conducted to generate regions of interest reflecting regions of converging activation across studies. These regions of interest were applied to the present data set.

\section{Studies selected for inclusion in analysis}

Twelve PET studies, which incorporated 25 active task conditions, were included in the analysis. Eight of the studies were selected because they were stated explicitly to be studies of either verbal (Paulesu et al., 1993; Petrides et al., 1993b; Awh et al., in press) or nonverbal (Petrides et al., 1993a; Smith et al., 1995; Courtney et al., in press; Haxby et al., in press; Owen et al., in press) working memory. Because verbal working memory is thought to involve phonological/articulatory processes, four studies that explicitly explored aspects of such processing also were included (Démonet et al., 1992, 1993; Zatorre et al., 1992; Fiez et al., 1995). It should be noted that this review of the literature was not intended to survey exhaustively all studies that may have involved working memory or phonological processing. Not considered, for instance, were studies using tasks not intentionally designed to require working memory or phonological processing, but that nonetheless may have necessitated such processing. Also, because of methodological differences that may affect the localization of regions of activation, several studies of working memory that have used functional magnetic resonance imaging were not included (Cohen et al., 1994; McCarthy et al., 1994); it should be noted, however, that the results of these studies also tend to converge on the same regions identified using $\mathrm{PET}$.

\section{Identification of areas of common acivation}

The significant activations reported from each of the 25 active task comparisons were classificd according to their locations in terms of the Brodmann areas described by Talairach and Tournoux (1988). For studies in which the active task conditions were compared with multiple control or task conditions (Petrides et al., 1993a,b; Awh et al., in press; Courtney et al., in press; Haxby et al., 


\begin{tabular}{|c|c|c|c|}
\hline Active task & $x$ & $y$ & $z$ \\
\hline \multicolumn{4}{|l|}{ Courtney et al. (in press) } \\
\hline Face memory & 28 & -78 & -12 \\
\hline Location memory & 26 & -76 & 20 \\
\hline \multicolumn{4}{|l|}{ Haxby et al. (in press) } \\
\hline Face memory (1 sec) & 34 & -64 & -16 \\
\hline Face memory ( $6 \mathrm{sec})$ & 14 & -94 & 12 \\
\hline Face memory $(6 \mathrm{sec})$ & 22 & -92 & -8 \\
\hline Face memory (6 sec) & 26 & -74 & -12 \\
\hline \multicolumn{4}{|l|}{ Owen et al. (in press) } \\
\hline Spatial monitoring II & 8 & -88 & 5 \\
\hline Spatial monitoring II & 9 & -90 & 20 \\
\hline Spatial monitoring III & 27 & -85 & 3 \\
\hline Spatial span & 11 & -90 & 20 \\
\hline \multicolumn{4}{|l|}{ Smith et al. (1995) } \\
\hline Spatial memory, exp 1 & 28 & -71 & 29 \\
\hline \multicolumn{4}{|l|}{ Zatorre et al. (1992) } \\
\hline Phonetic judgment & 15 & -93 & -11 \\
\hline Mean location & 22 & -83 & 6 \\
\hline $\mathrm{SD}$ & 9 & 10 & 16 \\
\hline
\end{tabular}

in press), only those activations found by comparison with the most basic sensorimotor control condition were classified (so that data from each active task would be represented only once). This process identified eight areas in which activation foci were found in nine or more of the task conditions (more than one-third of the total). These areas were located in the inferior parielal cortex (at or near Brodmann area 40) bilaterally, the premotor cortex (at or near lateral Brodmann area 6) bilaterally, the dorsolateral prefrontal cortex (at or near Brodmann areas 9 and 46) on the right, the frontal operculum (at or near Brodmann areas 44 and 45) on the left, the anterior cingulate cortex (at or near Brodmann areas
24 and 32) near the midline, and the extrastriate cortex (at or near Brodmann areas 18 and 19) on the right. The foci of activation found across the studies are summarized in Tables 4-8 and Figure 5. It is important to note that although we chose to focus on those regions of highest convergence across studies published previously, other regions of activation have been reported that may make important contributions to specific aspects of working memory. For example, across several studies of nonverbal working memory, activation has been identified at or near Brodmann area 47 on the right (Smith et al., 1995; Haxby et al., in press; Owen et al., in press), and in several cases significant or near-significant activation has been reported at or near Brodmann areas 9 and 46 on the left (Petrides et al., 1993a,b; Owen et al., in press).

\section{Analysis of activation found in the present study}

To compare formally the results of the present study with those areas of converging activation found in previous studies, regions of interest were defined based on these previous results and then were applied to data from the present study. For each of the eight areas in which a high degree of converging activation was found, the coordinates of all foci falling within the area were averaged together (see Tables 4-8 for the mean location within each area). The resulting mean coordinate locations defined the center of eight spherical regions of interest, which were applied to the 36 maintenance minus fixation individual difference images. For each region, the 3 regional magnitude values from each subject were averaged together, and the resulting 12 values for each region then were submitted to a one-tailed $t$ test. Also, to compare the locations of activation found in the present study with locations reported previously, for each identified region the location of the nearest peak-pixel $t$ value was located in the t-image derived from the entire maintenance minus fixation data set. To explore the effects of list condition, two sets of paired $t$ tests were used to explore differences between (1) the related and unrelated word conditions, and (2) between the average activation for the word

Table 5. Left and right BA 40 (parietal cortex) activation across studies

LEFT BA 40

\begin{tabular}{l} 
Active task \\
\hline Awh et al. (in press) \\
2-back letter memory \\
Letter memory \\
Paulesu et al. (1993) \\
Letter memory/rhyme detc \\
Petrides et al. (1993a) \\
Self-ordered pointing \\
Self-ordered pointing \\
Petrides et al. (1993b) \\
Externally ordered digits \\
Self-ordered digits \\
Sinith et dl. (1995) \\
Object memory, exp 1 \\
Object memory, exp 2 \\
Spatial memory, exp 2 \\
Zatorre et al. (1992) \\
Phonetic judgment
\end{tabular}

Mean location

SD

\section{$x$}

y

$-33$

$-24$

\section{$-46$}

$-55$

32

$-44$

$$
32
$$

$-32$

$-24$

$-47$

$-56$

$-50$

$-38$

$-35$

$$
-49
$$

$-35$

$-36$

$-36$

$-29$

$-33$

6
$-42$

$-41$

$-41$

$-59$

$-47$

8

\section{RIGHT BA 40}

Active task

Owen et al. (in press)

Spatial monitoring I

Spatial monitoring II

Spatial monitoring III

Paulcsu ct al. (1993)

Letter memory/rhyme detect

Petrides et al. (1993a)

Self-ordered pointing

Self-ordered pointing

Petrides et al. (1993b)

Externally ordered digits

Self-ordered digits

Self-ordered digits

Smith et al. (1995)

Spatial memory, exp 1

Spatial memory, exp 2 $x$

\begin{tabular}{rrr}
44 & -40 & 51 \\
40 & -44 & 51 \\
40 & -42 & 50 \\
54 & -32 & 24 \\
16 & -56 & 30 \\
23 & -56 & 33 \\
38 & -52 & 45 \\
31 & -62 & 42 \\
42 & -44 & 49 \\
37 & -42 & 38 \\
34 & -52 & 34 \\
& & \\
36 & -48 & 41 \\
10 & 9 & 9 \\
\hline
\end{tabular}

51 51 50 
Table 6. BA 24/32 (anterior cingulate) activation across studies

\begin{tabular}{lrrr} 
Active task & $x$ & $y$ & $z$ \\
\hline Awh et al. (in press) & & & \\
$\quad$ 2-back letter memory & 6 & 12 & 40 \\
$\quad$ Letter memory & & & 38 \\
Courtney et al. (in press) & & 20 & 36 \\
$\quad$ Face memory & -3 & 31 & 17 \\
Fiez et al. (1995) & & & \\
$\quad$ Auditory target detection & -18 & 24 & 28 \\
Haxby et al. (in press) & & & \\
$\quad$ Face memory (21 sec) & 5 & 25 & 36 \\
Owen et al. (in press) & 3 & 24 & 39 \\
$\quad$ Spatial monitoring I & & & \\
$\quad$ Spatial monitoring III & -7 & 34 & 26 \\
Petrides et al. (1993a) & -3 & 29 & 29 \\
$\quad$ Self-ordered pointing & 9 & 24 & 40 \\
$\quad$ Self-ordered pointing & & & \\
$\quad$ Self-ordered pointing & -11 & 25 & 22 \\
Petrides et al. (1993b) & & & \\
$\quad$ Self-ordered digits & -1 & 14 & 43 \\
Smith et al. (1995) & 1 & 14 & 43 \\
$\quad$ Object memory, exp 1 & & & \\
$\quad$ Spatial memory, exp 2 & -1 & 13 & 22 \\
Zatorre et al. (1992) & & & \\
$\quad$ Phonctic judgment & & & \\
$\quad$ Mean location & & & \\
SD & & & \\
\hline
\end{tabular}

conditions versus the activation found in the pseudoword condition.

When the regions were applied to the present study, significant activation was found in the anterior cingulate region $(p<0.05$, after Bonferroni correction for 8 comparisons). In addition, a strong trend toward activation ( $p<0.05$ before Bonferroni correction for 8 comparisons) was found in the premotor cortex bilaterally, the right dorsolateral prefrontal cortex, and the left frontal opercular cortex. Interestingly, no significant activation was detected in either the left or the right inferior parietal region or in the right extrastriate region. For those regions that showed a significant or near-significant trend toward activation, the nearest peak to each region of interest was within the range of the locations reported for previous studies.

No significant differences between the related and unrelated list conditions were found in any of the eight regions, but significant effects of lexicality (word vs pseudoword list conditions) were found in two regions: the anterior cingulate region and the left frontal opercular region $(p<0.05$ after a Bonferroni correction for 8 comparisons). For both regions, significantly greater activation was found for pseudowords than for words (see Table 10).

Although to a large degree the results of this analysis converge with the two-stage, regions-of-interest analysis presented above, the increases found in the anterior cingulate and premotor cortical regions bilaterally were not detected in our initial analysis. For these regions, the increases were relatively small or variable across list conditions and, for this reason, they did not meet the criteria for inclusion in the first stage of the two-stage analysis presented above.

\section{DISCUSSION}

The discussion below will concentrate on regions of positive change found in the present study and in previous studies of working memory. Negative changes also were found in the present study; some of these negative changes may reflect a general shift of attentional resources (Fiez et al., 1995; Courtney et al., in press), whereas others may reflect the need to suppress overt vocalization.

\section{Dorsolateral prefrontal cortex}

The activation of dorsolateral cortex across a number of functional imaging studies (see Table 8) is consistent with other evidence that the dorsolateral prefrontal cortex is involved critically in working memory (for review, see Fuster, 1989; GoldmanRakic, 1994). A review of the lasks associated with dorsolateral

Table 7. Left and right lateral BA 6 (premotor cortex) activation across studies

LEFT lateral BA 6

\begin{tabular}{|c|c|c|c|c|c|c|c|}
\hline Active task & $x$ & $y$ & $z$ & Active task & $x$ & $y$ & $z$ \\
\hline Awh et al. (in press) & & & & Awh et al. (in press) & & & \\
\hline 2-back letter memory & -28 & 1 & 52 & 2-back letter memory & 24 & 3 & 52 \\
\hline I etter memory & -48 & -6 & 40 & Owen et al. (in press) & & & \\
\hline Owen et al. (in press) & & & & Spatial monitoring I & 30 & 3 & 50 \\
\hline Spatial monitoring I & -28 & 1 & 54 & Spatial monitoring II & 25 & 10 & 56 \\
\hline Spatial monitoring II & -27 & 1 & 54 & Spatial monitoring III & 29 & 6 & 51 \\
\hline Spatial monitoring III & -24 & 5 & 54 & Spatial span & 25 & 8 & 50 \\
\hline Spatial span & -21 & 5 & 59 & Petrides et al. (1993a) & & & \\
\hline Petrides et al. (1993a) & & & & Self-ordered pointing & 23 & 8 & 44 \\
\hline Self-ordered pointing & -38 & 10 & 40 & Petrides ct al. (1993b) & & & \\
\hline Petrides et al. (1993b) & & & & Externally ordered digits & 25 & 6 & 60 \\
\hline Externally ordered digits & -32 & 5 & 53 & Self-ordered digits & 27 & 5 & 58 \\
\hline Self-ordered digits & -20 & 8 & 62 & Smith et al. (1995) & & & \\
\hline \multirow[t]{2}{*}{ Self-ordered digits } & -16 & 12 & 48 & Spatial memory, exp 1 & 28 & 1 & 45 \\
\hline & & & & Spatial memory, exp 2 & 29 & -2 & 45 \\
\hline Mean location & -28 & 4 & 52 & Mean location & 26 & 9 & 51 \\
\hline $\mathrm{SD}$ & 9 & 5 & 7 & $\mathrm{SD}$ & 2 & 4 & 6 \\
\hline
\end{tabular}

RIGHT lateral BA 6 


\section{Table 8. Left BA 44/45 and right BA 9/46 activation across studies}

I.FFT RA 44/45 (frontal operculum)

\begin{tabular}{|c|c|c|c|c|c|c|c|}
\hline & \\
\hline Active task & $x$ & $y$ & $z$ & Active task & $x$ & $y$ & $z$ \\
\hline Awh et al. (in press) & & & & Courtney et al. (in press) & & & \\
\hline 2-back letter memory & -42 & 17 & 22 & Face memory & 32 & 36 & 20 \\
\hline Letter memory & 55 & 3 & 20 & Haxby ct al. (in press) & & & \\
\hline Letter memory & -44 & 12 & 22 & Face memory (1 sec) & 42 & 41 & 8 \\
\hline Courtney et al. (in press) & & & & Face memory (1 sec) & 42 & 26 & 20 \\
\hline Face memory & -40 & 8 & 28 & Owen et al. (in press) & & & \\
\hline Demonet et al. (1992) & & & & Spatial monitoring I & 35 & 30 & 29 \\
\hline Detect phoneme sequence & -50 & 18 & 20 & Spatial monitoring II & 39 & 37 & 20 \\
\hline Detect phoneme sequence & -40 & 4 & 28 & Spatial monitoring II & 39 & 25 & 36 \\
\hline Fiez et al. (1995) & & & & Spatial monitoring III & 28 & 49 & 9 \\
\hline Auditory target detection & -37 & 16 & 8 & Spatial monitoring III & 31 & 37 & 23 \\
\hline Haxby et al. (in press) & & & & Petrides et al. (1993a) & & & \\
\hline Face memory $(1 \mathrm{sec})$ & -40 & 22 & 8 & Self-ordered pointing & 35 & 32 & 21 \\
\hline Face memory $(16 \mathrm{sec})$ & -42 & 18 & 4 & Petrides et al. (1993b) & & & \\
\hline Face memory (21 sec) & -44 & 20 & 8 & Externally ordered digits & 40 & 34 & 29 \\
\hline Paulesu et al. (1993) & & & & Externally ordered digits & 27 & 29 & 36 \\
\hline Letter memory/rhyme detect & -46 & 2 & 16 & Self-ordered digits & 38 & 39 & 26 \\
\hline Smith et al. (1995) & & & & Smith et al. (1995) & & & \\
\hline Object memory, exp 1 & -39 & 3 & 29 & Spatial memory, $\exp 2$ & 40 & 36 & 22 \\
\hline Zatorre et al. (1992) & & & & & & & \\
\hline Phonetic judgment & -48 & 3 & 24 & & & & \\
\hline Mean location & -44 & 11 & 18 & Mean location & 36 & 35 & 23 \\
\hline SD & 5 & 8 & 9 & $\mathrm{SD}$ & 5 & 6 & 8 \\
\hline
\end{tabular}

prefrontal activation reveals several interesting patterns. First, dorsolateral prefrontal activation has been found using a variety of stimulus types: words (this study), digits (Petrides et al., 1993b), letters (Cohen et al., 1994), figures (Petrides et al., 1993a; Smith el al., 1995), faces (Courtney el al., in press; Haxby el al., in press), and dots (McCarthy et al., 1994; Smith et al., 1995; Owen et al., in press). Activation also has been found using tasks intended to emphasize different types of working memory: spatial (McCarthy et al., 1994; Smith et al., 1995; Owen et al., in press), object (Smith et al., 1995), face (Courtney et al., in press; Haxby et al., in press), and verbal (this study) (Petrides et al., 1993b; Cohen et al., 1994). These results provide little evidence for functional divisions within the dorsolateral prefrontal cortex, although evidence from other methodologies suggests that such subregions exist (Wilson et al., 1993; Goldman-Rakic, 1994; Petrides, 1994). Several factors may account for this failure, including insufficient spatial resolution and inadequate control of subject strategies. A second observation is that dorsolateral prefrontal activation can be found both for tasks that require the active manipulation of information and for tasks that merely require the maintenance of information; such task differences have been used to make theoretical distinctions between working and short-term memory (Baddeley, 1992; Petrides, 1994). Finally, in all of the studies reviewed, activation in dorsolateral prefrontal cortex was stronger on the right than on

\section{Table 9. Regions from previous studies examined in the maintenance minus fixation condition}

Regions from previous studies

\begin{tabular}{lrrr}
\hline Area & \multicolumn{1}{c}{$x$} & \multicolumn{1}{c}{$y$} \\
\hline R BA 18/19 & 22 & -83 \\
L BA 40 & -33 & -47 & \\
R BA 40 & 36 & -48 & 41 \\
BA 24/32 & -2 & 22 & 33 \\
L LAT BA 6 & -28 & 4 & \\
R LAT BA 6 & 26 & 5 & \\
L BA 44/45 & -44 & 11 & \\
R BA 9/46 & 36 & 35
\end{tabular}

\footnotetext{
${ }^{a}$ Uncorrected $p<0.05$.
}

${ }^{b} p<0.05$ with Bonferroni correction for eight comparisons.

${ }^{c}$ No positive peak was found within $20 \mathrm{~mm}$ of the region.

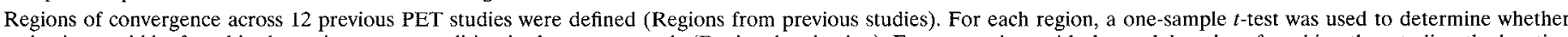

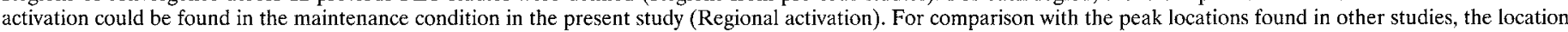

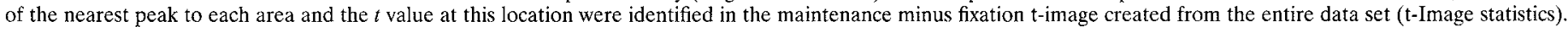


Table 10. Lexicality effects at regions defined from previous studies

Regions from previous studies

\begin{tabular}{|c|c|c|c|c|c|c|c|}
\hline & \multicolumn{2}{|c|}{ IVIean inagintude } & \multicolumn{2}{|c|}{1 alreal test } \\
\hline Area & $x$ & $y$ & $z$ & words & pseudowords & $t \mathrm{val}$ & $p$ val \\
\hline R BA $18 / 19$ & 22 & -83 & 6 & -15 & -1 & -0.90 & 0.3851 \\
\hline L BA 40 & -33 & -47 & 37 & 4 & -6 & 0.97 & 0.3516 \\
\hline $\mathrm{R} B A 40$ & -36 & -48 & 41 & 12 & 7 & 0.48 & 0.6432 \\
\hline BA $24 / 32$ & -2 & 22 & 33 & 18 & 51 & -4.29 & $0.0013^{a}$ \\
\hline L LAT BA 6 & -28 & 4 & 52 & 21 & 33 & -1.07 & 0.3089 \\
\hline R LAT BA 6 & 26 & 5 & 51 & 20 & 15 & 0.30 & 0.7689 \\
\hline L BA 44/45 & -44 & 11 & 18 & 4 & 39 & -5.21 & $0.0003^{a}$ \\
\hline R BA 9/46 & 36 & 35 & 23 & 19 & 12 & 0.82 & 0.4284 \\
\hline
\end{tabular}

${ }^{a} p<0.05$ with Bonferroni correction for eight comparisons.

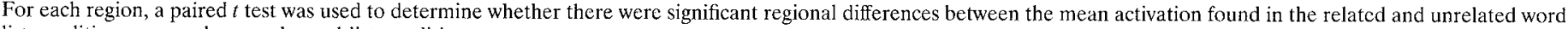
list conditions versus the pseudoword list condition.

the left. This hemispheric asymmetry is similar to differences noted previously in studies of episodic memory retrieval (Tulving et al., 1994; Buckner and Tulving, 1995; Buckner et al., 1995).

\section{Left frontal operculum}

Activation in the left frontal operculum (at or near Brodmamn areas 44 and 45) has been found in verbal working memory studies (Paulesu et al., 1993; Cohen et al., 1994; Awh et al., in press) and in studies of phonological processing (Démonet et al., 1992, 1993; Zatorre et al., 1992; Fiez et al., 1995). As suggested previously based on results across a number of disciplines (Paulesu et al., 1993; Fiez et al., 1995; Awh et al., in press), the left frontal operculum may be involved in some types of high-level acousticarticulatory processes. Such processes might contribute not only to specific aspects of subvocal rehearsal but also to a wider range of phonological, articulatory, and acoustic tasks. The effects of list condition and recall performance found in the present study are consistent with this interpretation. Activation within the frontal operculum was greatest in the pseudoword list condition, which may have required the most emphasis on articulatory rehearsal strategies because preexisting representations were not available to boost memory performancc. Furthermore, in a post hoc analysis comparison of subjects with perfect versus imperfect pseudoword recall, subjects with perfect recall had greater activation in the left frontal operculum, whereas subjects with poorer recall had greater activation in a left occipital region. One possibility is that subjects with perfect performance relied primarily on an articulatory strategy and that subjects with poor performance relied on a visually based strategy.

Several caveats should be noted, however. First, frontal opercular activation has been reported in studies of object and face working memory (Smith et al., 1995; Courtney et al., in press; Haxby et al., in press). Although some evidence suggests these activations resulted from subjects' adoption of verbal strategies (Smith et al., 1995; Courtney et al., in press), it is possible that the left frontal operculum is not involved exclusively in verbal processes. Second, there may be functional subregions within the frontal operculum, as suggested in part by the clustering of foci in Figure 5 and by the finding of multiple opercular regions in the present study. Resolving the specific contributions of regions within the frontal operculum will require additional studies. Third, because of inherent differences between words and pseudowords, maintaining a list of pseudowords places a greater memory load on the subject (Hulme et al., 1991; Multhaup et al., in press). Some of the activation differences found between words and pseudowords may reflect differences in task difficulty rather than inherent stimulus differences. For instance, the anterior cingulate may be sensitive to differences in memory load (Smith et al., 1995), which would explain why lexicality effects were found within the anterior cingulate in the present study. Additional studies in which list length and stimulus type are varied orthogonally will be necessary to resolve the effects of difficulty and stimulus type, which necessarily covaried in the present study.

\section{Motor areas (cerebellum, supplementary motor area, and premotor cortex)}

A wealth of data suggests that verbal material is maintained using an articulatory rehearsal system (Murray, 1968; Colle and Welsh, 1976; Baddeley, 1990) and that regions within the cerebellum and supplementary motor area (SMA) are likely candidates to form part of such a system (Paulesu et al., 1993; Awh et al., in press). In the present study, activation during both maintenance and silent counting tasks was found only in the cerebellum, whereas additional activation at or near the SMA was found in the maintenance condition. Similar cerebellar (Paulesu et al., 1993; Awh el al., in press) and SMA increases (Paulesu et al., 1993; Petrides et al., 1993b; Awh et al., in press) have been found in other verbal working memory studies. Interestingly, in both the present study and a study reported by Awh et al. (in press), greater SMA and cerebellar activation was found in a verbal working memory task than in a silent rehearsal task, providing evidence that the degree of cerebellar and SMA activation is affected by the memory load or the amount of covert articulation imposed by a task, or both. It also is important to note that the SM $\Lambda$ and cerebellum can be activated by nonverbal motor imagery tasks (Fox et al., 1987b; Decety and Ingvar, 1990; Decety et al., 1990), suggesting that the cerebellum and SMA are involved more widely in the generation of high-level internal motor representations.

Although cerebellar and SMA activation in working memory tasks appears to be associated with the use of a verbal rehearsal stratcgy, premotor cortex activation has been found using both verbal and nonverbal working memory tasks and tends to co-occur with dorsolateral prefrontal activation (see Tahles 8, 9). These results suggest that the premotor cortex plays a general role in working memory tasks. Based on single-unit recording studies of monkey premotor cortex, one possibility is that the premotor cortex is involved in maintaining a "motor set" across a delay 
interval (Weinrich and Wise, 1982; Boussaoud and Wise, 1993; Kurata and Hoffman, 1994).

\section{Left insular cortex}

The finding of significantly greater left insular activation in the silent counting than in the maintenance condition provides important evidence that the silent counting does not merely activate more weakly all of the areas involved in the maintenance condition. This finding is similar to differences observed when subjects read words aloud versus when they generated verbs in response to nouns. Insular activation was observed in the reading but not the verb generation task, whereas the converse pattern was observed in frontal areas (Raichle et al., 1994; Fiez et al., in press). With practice, activation in the verb generation task became statistically indistinguishable from activation in the reading task (Raichle et al., 1994). Based on these results, we have suggested that the insular regions are involved primarily in the production of overlearned, relatively "automatic" responses (Raichle et al., 1994; Fiez et al., in press). In this context, the silent counting task may be thought of as the covert production of a relatively automatic verbal sequence.

\section{Extrastriate and inferior parietal cortex}

Unlike a number of previous studies (see Tables 4,5 ), in the present study no significant changes were found in the right extrastriate cortex or the left or right inferior parietal cortex. Because the extrastriate changes have been related to aspects of visual processing (Courtney et al., in press; Haxby et al., in press), extrastriate activation was not anticipated in the present study. The failure to find inferior parietal activation is more surprising, but it does not necessarily contradict previous results. Regions within the inferior parietal cortex may be involved particularly in the encoding and/or retrieval of information, aspects of working memory that were minimized in the present study.

\section{REFERENCES}

Awh E, Jonides J, Smith EE, Schumacher EH, Koeppe R, Katz S (1996) Dissociation of storage and rehearsal in verbal working memory: evidence from PET. Psychol Sci, in press.

Baddcley A (1986) Working memory. Oxford: Clarendon.

Baddeley A (1990) Human memory: theory and practice. Needham Heights, MA: Allyn and Bacon:

Baddeley A (1992) Working memory. Science 255:556-559.

Battig WF, Montague WE (1969) Category norms for verbal items in 56 categories: a replication and extension of the Connecticut category norms. J Exp Psychol Monogr 80:1-46.

Boussaoud D, Wise SP (1993) Primate frontal cortex: effects of stimulus and movement. Exp Brain Res 95:28-40.

Brodmann K (1909) Vergleichende lokalisationslehre der grosshirnrinde in ihren prinzipien dargestellt auf grund des zellenbaues. Leipzig: J. A. Barth

Buckner RL, Tulving E (1995) Neuroimaging studies of memory: theory and recent PET results. In: Handbook of neuropsychology (Boller F, Grafman J, eds), pp 439-466. Amsterdam: Elscvier.

Buckner RL, Petersen SE, Ojemann JG, Miezin FM, Squire LR, Raichle ME (1995) Functional anatomical studies of implicit and explicit memory retrieval tasks. J Neurosci 15:12-29.

Casey PJ (1993) "That man's father is my father's son": the roles of structure, strategy, and working memory in solving convoluted verbal problems. Mem Cognit 21:506-518.

Cohen JD, Forman SD, Braver TS, Casey BJ, Servan-Schreiber D, Noll DC (1994) Activation of the prefrontal cortex in a nonspatial working memory task with functional MRI. Hum Brain Map 1:293-304.

Colle HA, Welsh A (1976) Acoustic masking in primary memory. J Verb Iearn Verb Rehav 15:17-32.

Corballis MC, Sidey S (1993) Effects of concurrent memory load on visualfield differences in mental rotation. Neuropsychologia 31:183-197.
Courtney SM, Ungerleider LG, Keil K, Haxby JV (1996) Object and spatial visual working memory activate separate neural systems in human cortex. Cereb Cortex, in press.

Decety J, Ingvar DH (1990) Brain structures participating in mental simulation of motor behavior: a neuropsychological interpretation. Acta Psychol 73:13-34.

Decety J, Sjoholm H, Ryding E, Stenberg G, Ingvar DH (1990) The cerebellum participates in mental activity: tomographic measurement of regional cerebral blood flow. Brain Res 535:313-317.

Démonet J-F, Chollet R, Ramsay S, Cardebat D, Nespoulous J, Wise R, Rascol A, Frackowiak RSJ (1992) The anatomy of phonological and semantic processing in normal subjects. Brain 115:1753-1768.

Démonet J-F, Price C, Wise R, Frackowiak RSJ (1993) A PET study of cognitive strategies in normal subjects during language tasks: influence of phonetic ambiguity and sequence processing on phoneme monitoring. Brain 117:671-682.

Fiez JA, Balota DA, Raichle ME, Petersen SE (1993) The effects of word frequency and spelling-to-sound regularity on the functional anatomy of reading. Soc Neurosci Abstr 19:1808.

Fiez JA, Raichle ME, Petersen SE (1996) Use of positron emission tomography to identify two pathways used for verbal response selection. In: Developmental dyslexia: neural, cognitive, and genetic mechanisms (Chase C, Rosen G, Sherman G, eds). Timonium, MD: York, in press.

Fiez JA, Tallal P, Raichle ME, Miezin FM, Katz WF, Petersen SE (1995) PET studies of auditory and phonological processing: effects of stimulus characteristics and task demands. J Cogn Ncurosci 7:357-375.

Ford I, McColl JH, McCormack AG, McCrory SJ (1991) Statistical issues in the analysis of neuroimages. $\mathbf{J}$ Cereb Blood Flow Metab 11:A89-A95.

Fox PT, Mintun MA (1989) Noninvasive functional brain mapping by change-distribution analysis of averaged PET images of $\mathrm{H}_{2}{ }^{15} \mathrm{O}$. J Nucl Med 30:141-149.

Fox PT, Perlmutter JS, Raichle ME (1985) A stereotactic method of anatomical localization for positron emission tomography. J Comput Assist Tomogr 9:141-153.

Fox PT, Miezin FM, Allman JM, Van Essen DC, Raichle ME (1987a) Retinotopic organization of human visual cortex mapped with positron emission tomography. J Neurosci 7:913-922.

Fox PT, Pardo JV, Petersen SE, Raichle ME (1987b) Supplementary motor and premotor responses to actual and imagined hand movement with positron emission tomography. Soc Neurosci Abstr 13:1433.

Fox PT, Mintun MA, Reiman EM, Raichle ME (1988) Enhanced detection of focal brain responses using intersubject averaging and changedistribution analysis of subtracted PET images. J Cereb Blood Flow Metab 8:642-653.

Friston KJ, Frith CD, Liddle PF, Frackowiak RSJ (1991) Comparing functional (PET) images: the assessment of significant change. J Cereb Blood Flow Metab 11:690-699.

Funahashi S, Bruce CJ, Goldman-Rakic PS (1989) Mnemonic coding of visual space in the monkey's dorsolateral prefrontal cortex. J Neurophysiol 61:331-349.

Fuster JM (1973) Unit activity in prefrontal cortex during delayedresponse performance: neuronal correlates of transient memory. J Neurophysiol 36:61-78.

Fuster JM (1989) Prefrontal cortex. In: Anatomy, physiology, and neuropsychology of the frontal lobe. New York: Raven.

Geary DD, Brown SC, Samaranayake VA (1991) Cognitive addition: a short longitudinal study of strategy choice and speed-of-processing differences in normal and mathematically disabled children. Dev Psychol 27:787-797.

Goldman-Rakic PS (1994) The issue of memory in the study of prefrontal function. In: Motor and cognitive functions of the prefrontal cortex (Thierry A-M, Glowinski J, Goldman-Rakic PS, Christen Y, eds), pp 112-121. New York: Springer.

Grasby PM, Frith CD, Friston KJ, Benclı C, Frackowiak RSJ, Dolan RJ (1993) Functional mapping of brain areas implicated in auditory-verbal memory function. Brain 116:1-20.

Haxby JV, Ungerleider LG, Horwitz B, Rapoport SI, Grady CL (1996) Hemispheric differences in neural systems for face working memory: a PET-rCBF study. Hum Brain Map, in press.

Herscovitch P, Markham J, Raichle ME (1983) Brain blood flow measured with intravenous $\mathrm{H}_{2}{ }^{15} \mathrm{O}$. I. Theory and error analysis. J Nucl Med 24:782-789.

Hertzog C, Rypma B (1991) Age differences in components of mentalrotation task performance. Bull Psychon Soc 29:209-212. 
Hulme C, Maughan S, Brown GDA (1991) Memory for familiar and unfamiliar words: evidence for a long-term memory contribution to short-term memory span. J Mem Lang 30:685-701.

Hunton DL, Miezin FM, Buckner RL, Raichle ME, Petersen SE (1994) An assessment of replicability and anatomical variability in functional neuroimaging studies. Soc Neurosci Abstr 20:354.

Jonides J, Smith EE, Koeppe RA, Awh E, Minoshima S, Mintun MA (1993) Spatial working memory in humans revealed by PET. Nature 363:623-625.

Just MA, Carpenter PA (1992) A capacity theory of comprehension: individual differences in working memory. Psychol Rev 99:122-149.

Kurata K, Iloffman D (1994) Differential effects of muscimol microinjection into dorsal and ventral aspects of the premotor cortex of monkeys. J Neurophysiol 71:1151-1164.

Logie RH, Gilhooly KJ, Wynn V (1994) Counting on working memory in arithmetic problem solving. Mem Cognit 22:395-410.

McCarthy G, Blamire AM, Puce A, Nobre AC, Bloch G, Hyder F, Goldman-Rakic P, Shulman RG (1994) Functional magnetic resonance imaging of human prefrontal cortex activation during a spatial working memory task. Proc Natl Acad Sci USA 91:8690-8694.

Miller GA (1956) The magical number seven, plus or minus two: some limits on our capacity for processing information. Psychol Rev 63:81-97.

Mintun MA, Fox PT, Raichle ME (1989) A highly accurate method of localizing regions of neuronal activation in the human brain with positron emission tomography. J Cereb Blood Flow Metab 9:96-103.

Multhaup KS, Balota DA, Cowan N (1996) Implications of aging, lexicality, and item length for the mechanisms underlying memory span. Psychon Bull Rev, in press.

Murray DJ (1968) Articulations and acoustic confusibility in short-term memory. J Exp Psychol 78:679-684.

Owen A, Evans AC, Petrides M (1996) Evidence for a two-stage model of spatial working memory processing within the lateral frontal cortex: a positron emission tomography study. Cereb Cortex, in press.

Paulesu E, Frith CD, Frackowiak RSJ (1993) The neural correlates of the verbal component of working memory. Nature 362:342-345.

Petrides M (1994) Frontal lobes and working memory: evidence from investigations of the effects of cortical excisions in nonhuman primates. In: I Iandbook of neuropsychology (Boller F, Grafman J, eds), pp 59-82. Amsterdam: Elsevier.

Petrides M, Alivisatos B, Evans AC, Meyer E (1993a) Dissociation of human mid-dorsolateral from posterior dorsolateral frontal cortex in memory processing. Proc Natl Acad Sci USA 90:873-877.
Petrides M, Alivisatos B, Meyer E, Evans AC (1993b) Functional activation of the human frontal cortex during the performance of verbal working memory tasks. Proc Natl Acad Sci USA 90:878-882.

Raczkowski D, Kalat JW, Nebes R (1974) Reliability and validity of some handedness questionnaire items. Neuropsychologia 12:43-47.

Raichle ME, Fiez JA, Videen TO, MacLeod AK, Pardo JV, Fox PT, Petersen SE (1994) Practice-related changes in human brain functional anatomy during non-motor learning. Cereb Cortex 4:8-26.

Rajkowska G, Goldman-Rakic PS (1995a) Cytoarchitectonic definition of prefrontal areas in the normal human cortex. I. Remapping of areas 9 and 46 using quantitative criteria. Cereb Cortex 5:307-322.

Rajkowska G, Goldman-Rakic PS (1995b) Cytoarchitectonic definition of prefrontal areas in the normal human cortex. II. Variability in locations of areas 9 and 46 and relationship to the Talairach coordinate system. Cereb Cortex 5:323-337.

Smith EE, Jonides J, Koeppe RA, Awh E, Schumacher EH, Minoshima S (1995) Spatial vs. object working memory: PET investigations. J Cogn Neurosci 7:337-356.

Talairach J, Tournoux P (1988) Co-planar stereotaxic atlas of the human brain (Rayport $M$, transl). New York: Thieme.

Ter-Pogossian MM, Ficke DC, Hood JT, Yamamoto M, Mullani NA (1982) PETT VI: a positron emission tomograph utilizing cesium fluoride scintillation detectors. J Comput Assist Tomogr 6:125-133.

Tulving E, Kapur S, Craik FIM, Habib R, Houle S (1994) Hemispheric encoding/retrieval asymmetry in episodic memory: positron emission tomography findings. Proc Natl Acad Sci USA 91:2016-2020.

Weinrich M, Wise SP (1982) The premotor cortex of the monkey. J Neurosci 2:1329-1345.

Welch M, Kilbourn M (1985) A remote system for the routine production of oxygen-15 radiopharmaceuticals. J Labelled Compd Radiopharm 22:1193-1200.

Wilson FAW, O'Scalaidhe SP, Goldman-Rakic PS (1993) Dissociation of object and spatial processing domains in primate prefrontal cortex. Science 260:1955-1958.

Worsley KJ, Evans AC, Marrett S, Neelin P (1992) A three dimensional statistical analysis for CBF activation studies in human brain. $\mathbf{J}$ Cereb Blood Flow Metab 12:900-918.

Yamamoto M, Ficke DC, Ter-Pogossian M (1982) Performance study of PETT VI, a positron computed tomograph with 288 cesium fluoride detectors. IEEE Trans Nucl Sci 29:529-533.

Zatorre RJ, Evans AC, Meyer E, Gjedde A (1992) Lateralization of phonetic and pitch discrimination in speech processing. Science 256: $846-849$. 